\title{
C\&C - Contraction and Convergence of Carbon Emissions: The Economic Implications of Permit Trading
}

Christoph Böhringer ${ }^{\mathrm{a}}$ and Heinz Welsch ${ }^{\mathrm{b}}$

\begin{abstract}
In the context of climate protection policy it has been suggested that global $\mathrm{CO}_{2}$ emissions should be reduced significantly (contraction) and that per capita emissions should gradually be equalized across countries (convergence). This paper uses a dynamic multi-region computable general equilibrium model of the world economy to assess the economics of "Contraction and Convergence" (C\&C). In comparing a regime of tradable and non-tradable emission rights for implementing $\mathrm{C} \& \mathrm{C}$ we find that the former allows to reduce long-term costs of abatement in terms of Hicksian equivalent variation in lifetime income by more than $50 \%$ percent in comparison with the latter. Under a tradable permit regime some developing countries improve their economic welfare even beyond non-abatement baseline levels. A decomposition of the general equilibrium effects associated with $C \& C$ shows that changes in the terms of trade constitute a key determinant of the overall welfare effects.
\end{abstract}

\section{Key words:}

climate protection, international equity, emissions trading, economic welfare, computable general equilibrium modeling

\section{JEL classifications:}

Q2, Q4, D58

${ }^{\mathrm{a}}$ Zentrum für Europäische Wirtschaftsforschung (ZEW, Centre for European Economic

Research), Mannheim, Germany

${ }^{\mathrm{b}}$ Universität Oldenburg (University of Oldenburg), Oldenburg, Germany

Helpful comments were received by Thomas Rutherford. Contact the authors at: BOEHRINGER@ZEW.DE or WELSCH@UNI-OLDENBURG.DE 


\section{Table of Contents}

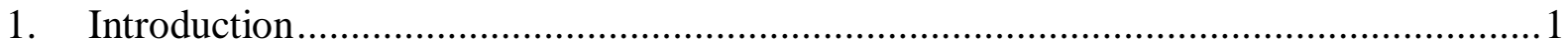

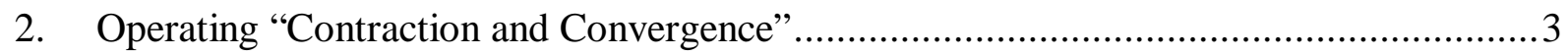

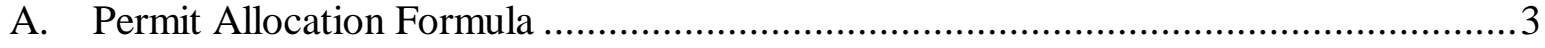

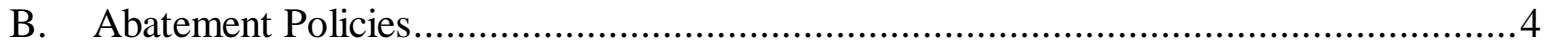

3. Model Characteristics and Parameterization ...............................................................4

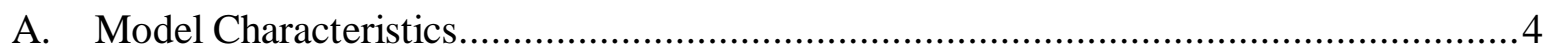

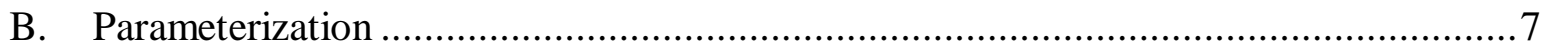

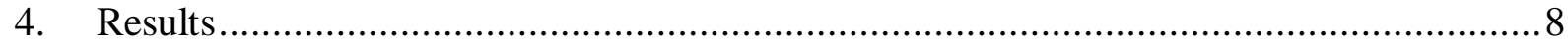

A. Emissions and Marginal Abatement Costs ...................................................................

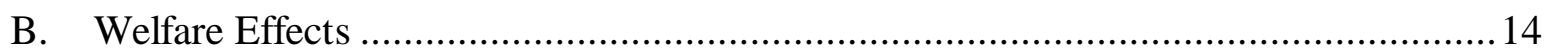

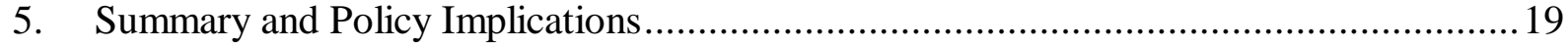

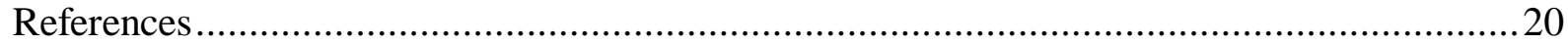

\section{List of Tables and Figures}

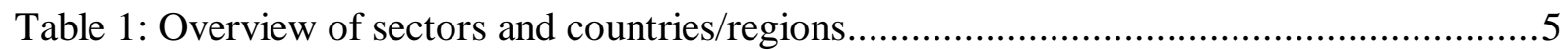

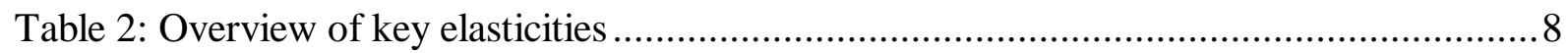

Table 3: Per capita emission endowments by region ......................................................

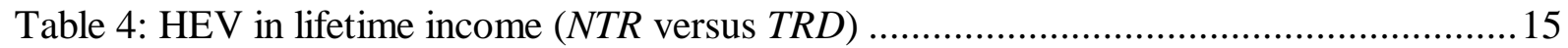

Table 5: Decomposition of HEV in lifetime income under NTR ....................................... 17

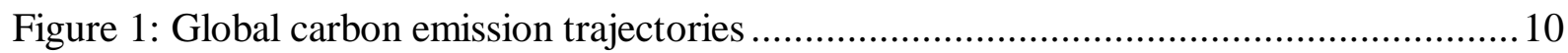

Figure 2a-j: Emission profiles at country level ........................................................... 10

Figure 3: Carbon taxes under NTR below global TRD permit price.................................... 13

Figure 4: Carbon taxes under NTR above global TRD permit price.................................... 13

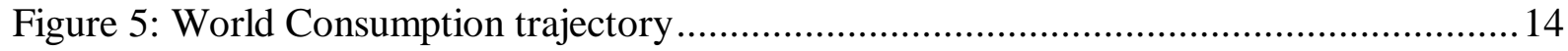




\section{Introduction}

In order to mitigate the expected climate change arising from the atmospheric accumulation of $\mathrm{CO}_{2}$ and other trace gases, a significant contraction of global greenhouse gas emissions is widely postulated. These requests date back at least to the so-called Toronto summit in 1988, in which reduction rates of up to 50 percent by the year 2050 have been suggested. More recently, the Intergovernmental Panel on Climate Change (IPCC) has stated that in order to avoid an increase of the global mean temperature by more than 2 degrees Celsius by the end of the next century, global emissions will have to start declining soon; by 2050 they will have to be reduced by roughly 25 percent below current levels (Houghton et al. 1996).

In a similar vein, the Global Commons Institute has devised a greenhouse gas abatement proposal called "Contraction and Convergence" (Global Commons Institute 1997), in which the emphasis is placed not only on a significant contraction of anthropogenic $\mathrm{CO}_{2}$ emissions, but also on an equitable per capita distribution of the resulting global carbon budget. The latter implies a transition to a point (convergence) where future entitlements to emit will have become proportional to population. The uniform per capita allocation of emission rights reflects egalitarianism in the sense that all people have inherently an equal right to pollute. The egalitarian criterion per se has a strong philosophical appeal. However - under contraction of the global carbon budget - it is unlikely to be acceptable for industrialized countries with currently high per capita emissions unless the transition path allows for long-term "smooth" adjustment towards the terminal point.

Equity considerations are not only ethically founded; they also conform to the idea that equity might "serve a positive role as a unifying principle that facilitates an international greenhouse warming agreement" (Rose and Stevens, 1996 p.1). Many analysts of the issue have concluded that greater cooperation is likely to be forthcoming if the cooperation agreement is perceived to be fair (see, e.g. Morrisette and Plantinga 1991, Bohm and Larsen 1994).

The outcome of the Kyoto conference in December 1997 backs this proposition though concepts of equity have remained rather vague during the negotiation process. Equity considerations are nevertheless implicit to the Kyoto Protocol. In fact, the industrialized (Annex B) countries have committed themselves to reduce greenhouse gas emissions to varying degrees, apparently meaning to reflect differences in the "ability to pay". Equity can 
also be invoked to justify that developing countries have, as yet, not made any commitment to greenhouse gas abatement.

The provisions of the Kyoto Protocol are of a relatively short-term nature (2008-2012). The Kyoto emission limits for the industrialized countries will not prevent global carbon emissions to grow significantly for reasonable baseline assumptions of economic development and future fossil fuel consumption in developing countries. In view of the long-term reduction requirements mentioned above further reduction obligations for industrialized countries and some emission cap for developing countries will be necessary. Cooperation by developing countries is likely only if they perceive their share in the global long-term carbon budget as fair. On part of the developing world this comes effectively down to an equal per capita allocation of emission rights (Rose and Stevens 1996).

Apart from explicit equity considerations the opportunities for coordinated abatement policies play another major role in climate policy negotiations. To reduce costs of abatement the Kyoto Protocol in principle allows for the use of flexible mechanisms such as joint implementation (JI), clean development mechanisms (CDM) or emissions trading (ET). These so-called Kyoto instruments exploit differences in marginal abatement costs across regions. On the latest Conference of Parties at Buenos Aires (1998) increasing emphasis has been placed on the use of globally tradable emission rights to ensure minimization of global abatement costs. ${ }^{1}$

Overall, it appears that the "Contraction and Convergence" paradigm $(\mathrm{C} \& \mathrm{C})$, merged with the idea of tradable permits, could serve as a unifying concept to operate climate protection in the long run. A precursor of such an approach has been proposed by Welsch (1993). In the current paper we use a dynamic multi-region computable general equilibrium model of the world economy (Bernstein, Montgomery and Rutherford 1997, Böhringer and Rutherford 1999a) to assess the economics of this proposal. Our most important conclusion is that adoption of the "Contraction and Convergence" paradigm at the global level will be much easier if emission rights are tradable. Restrictions to permit trade impose significantly higher costs on the world economy. Moreover, a tradable permit regime allows some developing countries to significantly improve their economic welfare beyond non-abatement baseline levels. A decomposition of the general equilibrium effects shows that changes in the terms of trade play an important role for explaining the overall welfare effects.

\footnotetext{
${ }^{1}$ In fact, national parliaments of several Annex 1 countries - the so-called JUSCANZ countries or UMBRELLA group - have put acceptance of the Kyoto Protocol under condition that international emissions trading can be used as a flexible mechanism to meet national reduction targets.
} 
In section 2 we explain how the $\mathrm{C} \& \mathrm{C}$ formula is operated to derive the emission budgets of regions along the timepath; we also sketch the abatement policies to be analyzed in the current paper. In section 3 we describe the basic features and the parameterization of our modeling framework. In section 4 we present results, and in section 5 we offer policy conclusions.

2.

Operating "Contraction and Convergence"

A.

\section{Permit Allocation Formula}

With respect to "Contraction" we assume that global carbon emissions are to be reduced by 25 percent in 2050 relative to 1990. In accordance with "Convergence", it is postulated that each person in the world should have an equal share in the resulting stock of carbon emission rights in 2050. The emission quotas for the period before 2050 should reflect differences in present per capita emissions, in order to facilitate smooth adjustment in highemission countries.

More specifically, assume that the allotment of long-term carbon rights comes into force by the year 2000 . Let $t=1,2, \ldots, 50$ refer to the years $2001,2002, \ldots, 2050$. Then the per capita emission rights of country $i$ in year $t, z_{i}(t)$, should be a weighted average of per capita emissions in 2000 and the uniform per capita right valid in 2050:

$$
z_{i}(t)=\frac{50-t}{50} \cdot z_{i}(2000)+\frac{t}{50} \cdot z
$$

where: $\quad z_{i}(2000)=$ per capita emissions in 2000 in country $i$, $z=$ uniform per capita emission right in 2050.

The total carbon limit $C A R B L I M_{i}(t)$ for a country in a certain year is obtained by multiplying the per capita emission right by the country's population $\operatorname{POP}_{i}(t)$ in that year:

$$
\operatorname{CARBLIM}_{i}(t)=z_{i}(t) \cdot P O P_{i}(t)
$$

Of course, in implementing this formula, it is important to use population projections fixed ex ante, in order to avoid incentives for population growth. Adding the carbon limits across countries defines the global carbon limit. 
This procedure gives a gradual adjustment in both total emissions and in the distribution of emission rights across countries, in line with the contraction and convergence paradigm.

\section{B. Abatement Policies}

In our simulations (see section 4 below) we distinguish between two abatement regimes which capture the extreme points of non-cooperative and cooperative carbon abatement policy:

NTR: The carbon limits CARBLIM strictly apply at the country level. In other words, countries are not allowed to buy or sell emission permits on international markets. All emission reductions must take place domestically.

TRD: Emission rights can be traded across borders. There are no restrictions to the eligibility of trading partners and the magnitude of emission trade.

Throughout the simulations we treat emission limitations as a resource constraint. We then can interpret the shadow price on the emission constraint, i.e. the marginal abatement costs, as the carbon tax rate or likewise the price of the non-tradable / tradable emission rights. In the TRD case there will be an equalization of marginal abatement costs across countries. Revenues from carbon taxes or permits enter the national accounts in each region.

3. Model Characteristics and Parameterization

\section{A. Model Characteristics}

The current model features 10 regions (countries) which are linked through bilateral trade flows. The economic structure of each region consists of 4 production sectors (1 nonenergy sector and 3 fossil fuel sectors) whose outputs are demanded by intermediate production, exports, investment and a representative consumer. Table 1 gives an overview of the regional and sectoral aggregation, which is based on GTAP data for 30 regions and 38 sectors (McDougall, 1995). Producers and representative consumers behave according to the competitive paradigm, in the sense that they take market prices as given. Consumption and investment decisions are based on rational point expectations of future prices. The representative agent for each region maximizes lifetime utility from consumption which implicitly determines the level of savings. Entrepreneurs choose investment in order to 
maximize the present value of their firms. We provide a non-technical description of the intertemporal multi-sector, multi-region model. ${ }^{2}$

Table 1: Overview of sectors and countries/regions (data base: GTAP 3.0; see McDougall, 1995)

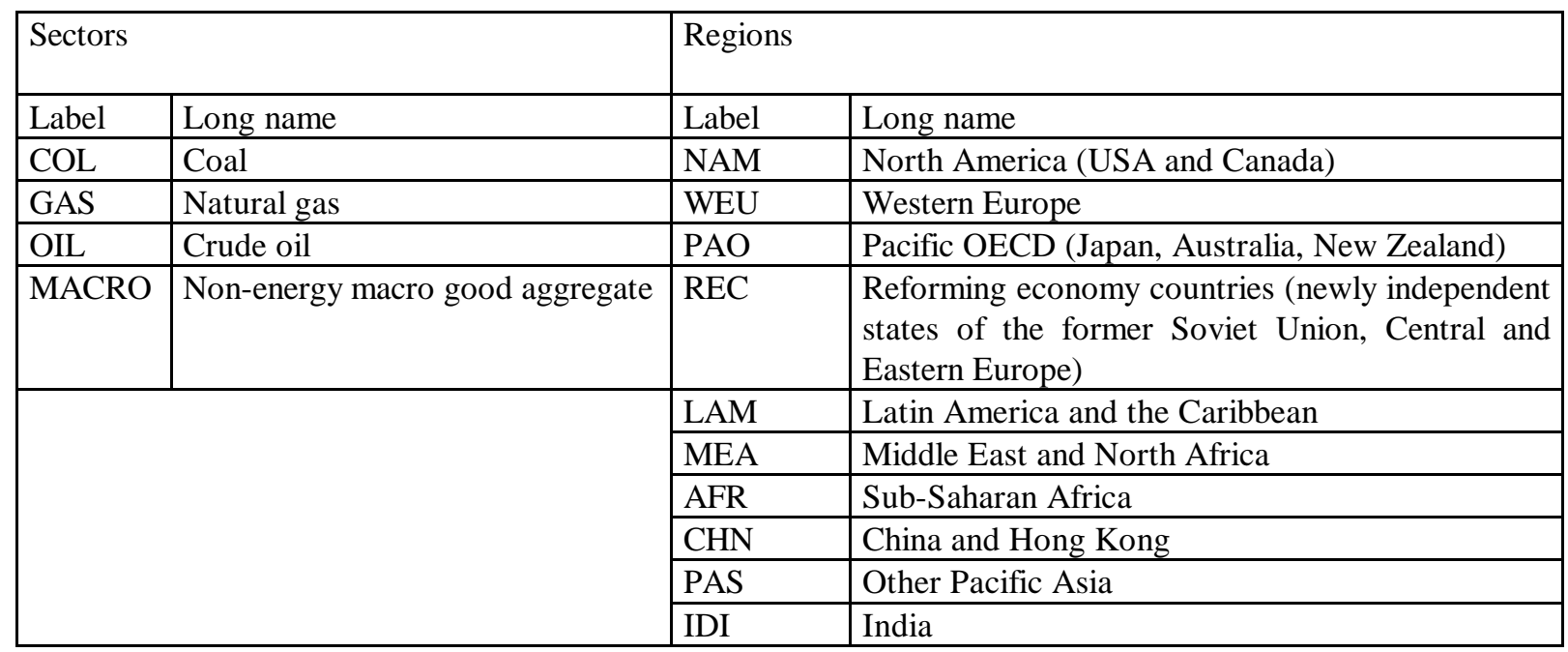

\section{Production}

In each region production of the non-energy macro good is captured by an aggregate production function which characterizes technology through transformation possibilities on the output side (between production for domestic and export markets) and substitution possibilities on the input side (between alternative combinations of inputs). On the output side production is split between goods produced for the domestic markets and goods produced for the export market subject to a constant elasticity of transformation. On the input side capital, labor and an energy aggregate of fossil fuels trade off with a constant elasticity of substitution. Production of the energy aggregate is described by a CES function which reflects substitution possibilities for different fossil fuels (i.e., coal, gas, and oil). Fossil fuels are produced from fuel-specific resources and the non-energy macro good subject to a CES technology. The elasticity of substitution between the resource input and non-energy inputs is calibrated to match a given price elasticity of supply. Depletion leads to rising fossil fuel prices at constant demand quantities, but the relationship between depletion rates, fossil energy stocks and fuel production is not incorporated (i.e. the model has no stock accounting of fossil fuels).

\footnotetext{
${ }^{2}$ An algebraic model summary can be obtained from the authors on request.
} 


\section{Household Behavior}

In each region a representative household chooses to allocate lifetime income across consumption in different time periods in order to maximize lifetime utility. In each period households face the choice between current consumption and future consumption, which can be purchased via savings. That is, consumption and the level of savings are endogenously determined in each period. The trade-off between current consumption and savings is given by a constant intertemporal elasticity of substitution. Households demand an aggregate consumption good, which is a CES composite of the non-energy macro good and a householdspecific energy aggregate.

\section{Investment}

Managers of the firms invest as long as the marginal return on investment equals the marginal cost of capital formation. The rates of return are determined by a uniform and endogenous world interest rate such that the marginal productivity of a unit of investment and a unit of consumption is equalized within and across countries.

\section{International Trade}

Following Armington (1969), domestic, imported and exported varieties of the nonenergy goods are distinguished by origin. The Armington aggregation function provides a constant elasticity of substitution between domestic and imported varieties for the non-energy good for all buyers in the domestic market. With respect to trade in energy, fossil fuels from different regions are treated as perfect substitutes, which implies that we use net trade data with no cross-hauling. International capital flows reflect borrowing and lending at the world interest rate, and are endogenous subject to an intertemporal balance of payments constraint: there is no change in net indebtedness over the entire model horizon, i.e., net-indebtedness is the same at the initial and at the terminal point.

\section{Backstop Technologies}

In each region there are backstop technologies for producing the industrial energy aggregate or the household energy aggregate. The backstop technology defines the price for a carbon free energy source (e.g. photovoltaic, fuel cells) and hence implicitly determines an upper limit on the marginal costs of reducing carbon emissions. ${ }^{3}$

\footnotetext{
${ }^{3}$ In the baseline parametrization the cost of the backstop fuel is six times the price of the region's (industrial/household) energy composite for the baseyear 1992.
} 


\section{B. Parameterization}

Benchmark data are used to calibrate parameters of the functional forms from a given set of quantities, prices and elasticities. Data from four different sources are combined to yield a consistent benchmark data set:

- GTAP database (McDougall, 1995). GTAP includes detailed input-output tables for 37 sectors in 30 regions and a world trade matrix with bilateral trade flows for all sectors and regions.

- IEA energy balances and energy prices/taxes (IEA, 1994). IEA provides statistics on physical energy flows and energy prices for industrial and household demands.

- WEC/IIASA (IIASA, 1998). WEC/IIASA makes projections on the future development of world GDP and fossil fuel production for the $21^{\text {st }}$ century differentiated by countries.

- Bank for International Reconstruction and Development (Bos et al. 1992). This source provides data on population growth till 2050 for 194 countries plus summary groups.

We replace GTAP's aggregate input-output monetary values for energy supply and demand with physical energy flows and energy prices as given in IEA's energy statistics. This "bottom-up" calibration of energy demands and supplies yields sector-specific and energyspecific $\mathrm{CO}_{2}$ coefficients. The advantage is that marginal abatement cost curves and hence the cost evaluation of emission constraints are based on actual energy flows rather than aggregate monetary data, which strengthens the credibility of the quantitative results.

Dynamic models in applied CGE analysis are often calibrated to a steady-state growth path in which all physical quantities grow at exogenous rates. ${ }^{4}$ In our analysis we incorporate the exogenous WEC/IIASA assumptions on non-uniform growth rates for GDP and fossil fuel production across countries. ${ }^{5}$ The exogenous assumptions on fossil fuel production for our business as usual $(B A U)$ scenario imply a reference emission level for the world as a whole. At the country level the $B A U$ emission trajectory determines the extent to which potential reduction obligations with respect to a reference year (in our case: 1990) bind in the future. ${ }^{6}$

\footnotetext{
${ }^{4}$ The virtue of the steady-state calibration is that the amount of exogenous information which goes beyond the explanatory scope of the model is kept at a minimum.

${ }^{5}$ See Böhringer, Jensen and Rutherford (1999) for calibration routines to match GDP forecasts with energy production projections.
}

${ }^{6}$ See Böhringer, Jensen and Rutherford (1999) on the importance of baseline assumptions for the magnitude and distribution of abatement costs. 
Population projections determine the carbon budget trajectory CARBLIM for each region according to our permit allocation formula (given a $25 \%$ cutback of global carbon emissions in 2050 as compared to 1990 world emission levels).

Table 2 summarizes the central values for key elasticities employed for the core simulations.

Table 2: Overview of key elasticities

\begin{tabular}{|c|c|c|}
\hline Type of elasticity & Description & Central Value \\
\hline Armington elasticity of substitution & $\begin{array}{l}\text { Degree of substitutability } \\
\text { - between macro imports from different } \\
\text { regions } \\
\text { - between the import aggregate and the } \\
\text { domestically produced macro good }\end{array}$ & $\begin{array}{l}2 \\
1\end{array}$ \\
\hline Armington elasticity of transformation & $\begin{array}{l}\text { Degree of substitutability between macro } \\
\text { good produced for the domestic market and } \\
\text { macro good destined for the export market }\end{array}$ & 2 \\
\hline Price elasticity of fossil fuel supply & $\begin{array}{l}\text { Degree of response of international fossil } \\
\text { fuel supply to changes in fossil fuel price }\end{array}$ & $\begin{array}{l}1 \text { (coal), } 4 \text { (gas), } 8 \\
\text { (oil) }\end{array}$ \\
\hline $\begin{array}{l}\text { Elasticity of substitution between non- } \\
\text { energy and energy composite in } \\
\text { production and final demand }\end{array}$ & $\begin{array}{l}\text { This value increases linearly over time } \\
\text { between a short-run value and the long-run } \\
\text { value to reflect empirical evidence on } \\
\text { differences between short-run and long-run } \\
\text { adjustment costs (Lindbeck, 1983) }\end{array}$ & $\begin{array}{l}0.2 \text { (short run: 2000) } \\
1.0 \text { (long run: 2050) }\end{array}$ \\
\hline Interfuel elasticity of substitution & $\begin{array}{l}\text { Degree of substitutability between fossil } \\
\text { fuels (fuel switching) }\end{array}$ & $\begin{array}{l}0.5 \text { (final demand) } \\
2^{\mathrm{a}}, 1^{\mathrm{b}} \text { (industry) }\end{array}$ \\
\hline
\end{tabular}

${ }^{a}$ between oil and gas, ${ }^{b}$ between coal and the oil-gas aggregate

\section{Results}

\section{A. Emissions and Marginal Abatement Costs}

The overall carbon limit in 2050 together with the population projections implies a reduction of world per-capita emissions from 1.065 tons of carbon in 2000 to 0.48 tons in 2050. Table 3 summarizes the per capita endowment with carbon emission rights across regions emerging from the $\mathrm{C} \& \mathrm{C}$-formula.

By definition of our C\&C-formula the terminal value in 2050 is identical for all regions. The initial value, however shows a tremendous dispersion, ranging from 0.21 tons for AFR to 5.2 tons for NAM. This dispersion reflects the current "inequities" in per capita emissions between the industrialized regions and developing countries. It should be noted however that except for AFR and IDI all regions have to cut back their emissions per capita (of course, by varying degrees) relative to current levels. 
Table 3: Per capita emission endowments by region (in tons of carbon per capita)

\begin{tabular}{l|llllll} 
Year & 2000 & 2010 & 2020 & 2030 & 2040 & 2050 \\
\hline CHN & 0.72 & 0.67 & 0.62 & 0.58 & 0.53 & 0.48 \\
REC & 1.83 & 1.56 & 1.29 & 1.02 & 0.75 & 0.48 \\
IDI & 0.22 & 0.27 & 0.32 & 0.38 & 0.43 & 0.48 \\
MEA & 0.55 & 0.54 & 0.53 & 0.51 & 0.50 & 0.48 \\
NAM & 5.23 & 4.28 & 3.33 & 2.38 & 1.43 & 0.48 \\
WEU & 2.75 & 2.29 & 1.84 & 1.39 & 0.93 & 0.48 \\
PAO & 2.87 & 2.39 & 1.91 & 1.44 & 0.96 & 0.48 \\
LAM & 0.58 & 0.56 & 0.54 & 0.52 & 0.50 & 0.48 \\
AFR & 0.21 & 0.27 & 0.32 & 0.37 & 0.43 & 0.48 \\
PAS & 0.68 & 0.64 & 0.60 & 0.56 & 0.52 & 0.48 \\
WORLD & 1.07 & 0.91 & 0.77 & 0.66 & 0.56 & 0.48 \\
\hline
\end{tabular}

Figure 1 and Figure 2 depict the carbon trajectories under $B A U, N T R$ and TRD together with the mandated timepath of emission rights CARBLIM which comes from our C\&C-formula. Under $B A U$, global emissions increase from $6 \mathrm{Gt}$ carbon in 2000 to roughly 11.5 Gt carbon in 2050 (see Figure 1). This $B A U$ trajectory is in line with the IIASA-WEC scenario B (middle course). By 2050 the administered global carbon limit of $4.4 \mathrm{Gt}$ is more than $60 \%$ below $B A U$ emissions which indicates the need for substantial adjustment towards less carbon-intensive production and consumption patterns. At the global level, strictly domestic abatement action (NTR) involves less carbon emissions than free trade in permit rights $(T R D)$. The reason is that regions IDI, AFR and MEA do not face a binding carbon constraint, i.e. they do not use their emission rights to the full extent possible. As Figures $2 \mathrm{~g}$, $2 \mathrm{~h}$ and $2 \mathrm{j}$ show, these regions have a substantial increase of emissions under NTR as compared to $B A U$. This is a phenomenon related to a shift in comparative advantage, as will be explained below.

When emission rights get tradable IDI, MEA and AFR use their carbon budget to the full extent possible which leads to an effective increase in global carbon emissions of roughly $10 \%$ by 2050 as compared to the NTR case. This phenomena has been referred to as hot air (Herold 1998, Greenpeace 1998).

The magnitude of the marginal abatement cost in the NTR case depends crucially on the extent to which the carbon emission constraint binds the respective economies. The effective reduction requirement for the different regions at any point over time is given by the distance between $B A U$ and CARBLIM. The higher the effective cut-back, the higher are - ceteris paribus - the carbon taxes necessary to meet the emission constraint. 
Figure 1: Global carbon emission trajectories

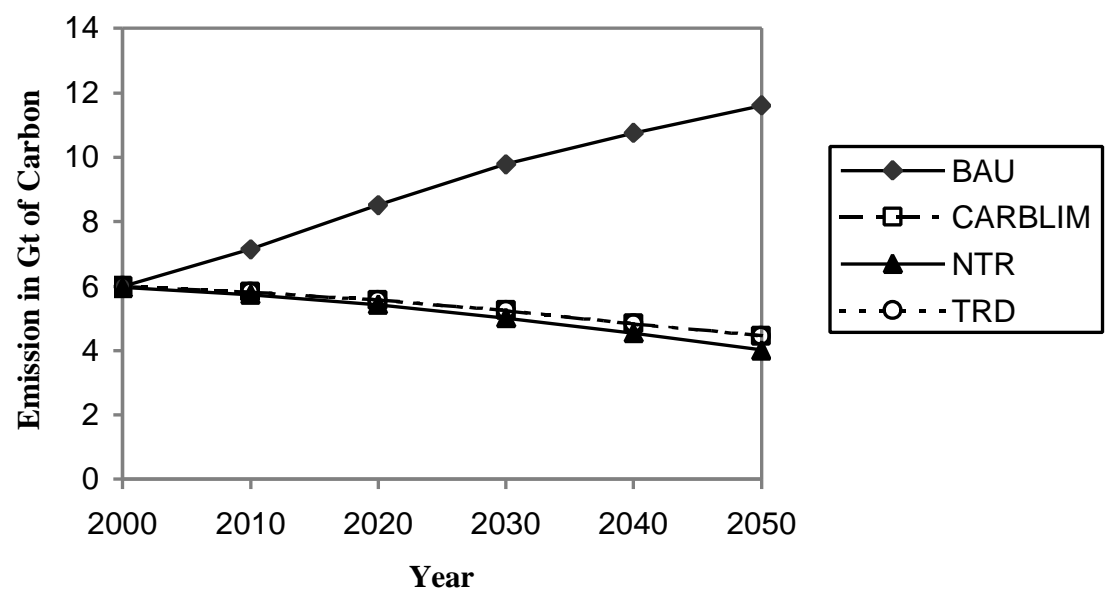

Figure 2a-j: Emission profiles at country level

Fig. 2a : Emissions in Country NAM

Fig. 2b : Emissions in Country WEU

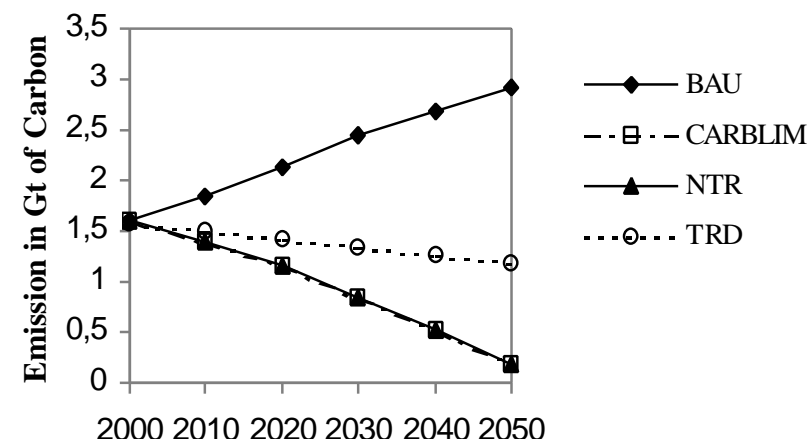

Year

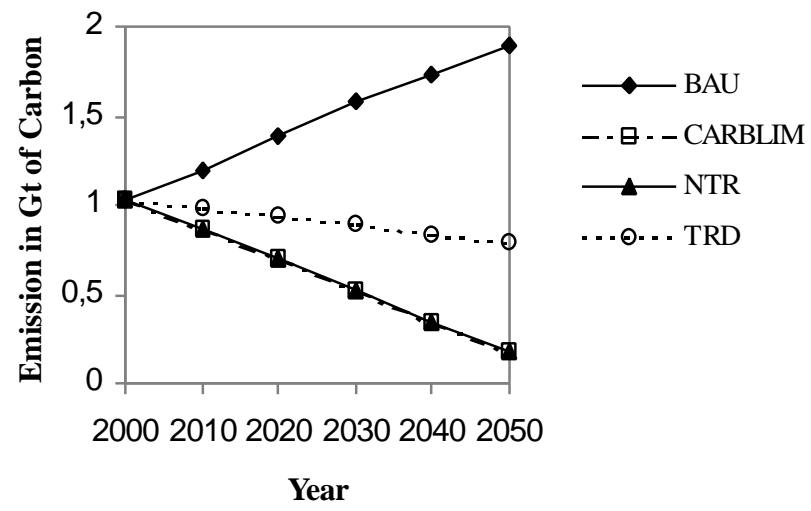

Fig. 2c : Emissions in Country PAO

Fig. 2d : Emissions in Country REC
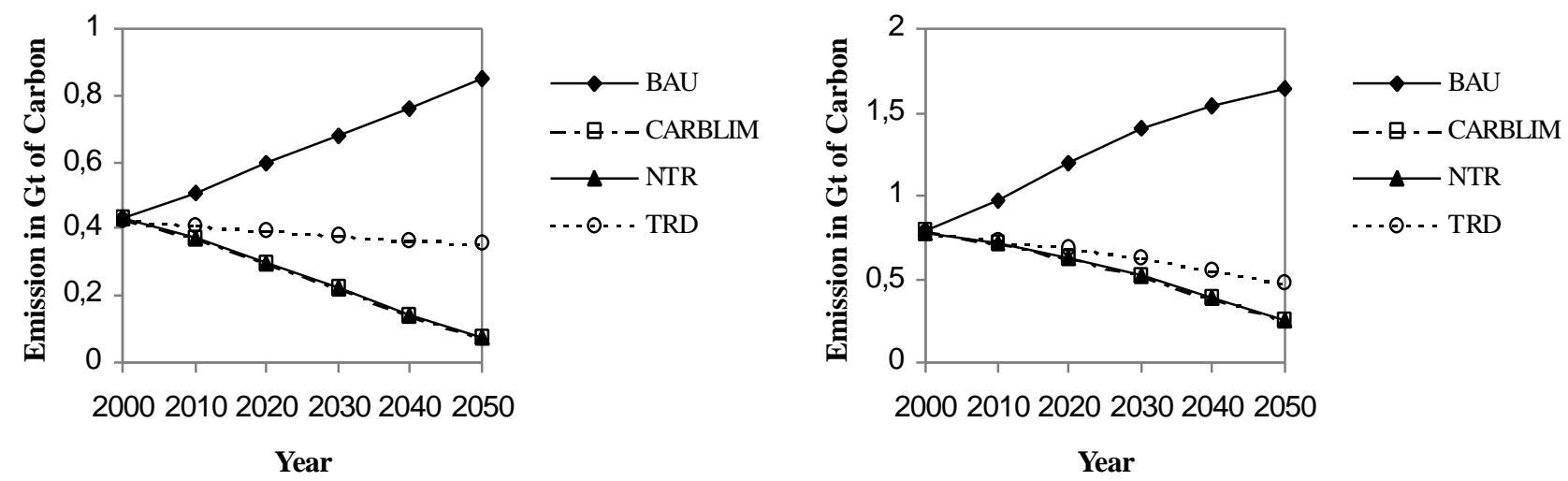
Figure 2a-2j: Emission profiles at country level

Fig. 2e : Emissions in Country LAM

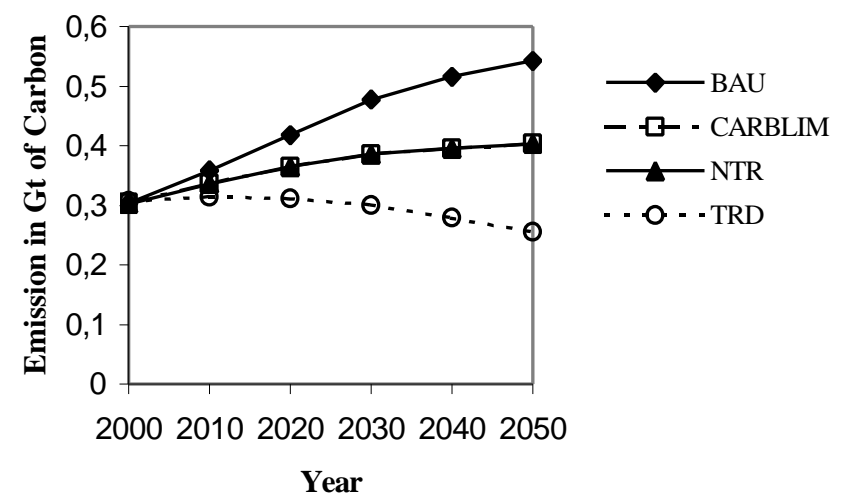

Fig. 2g : Emissions in Country AFR

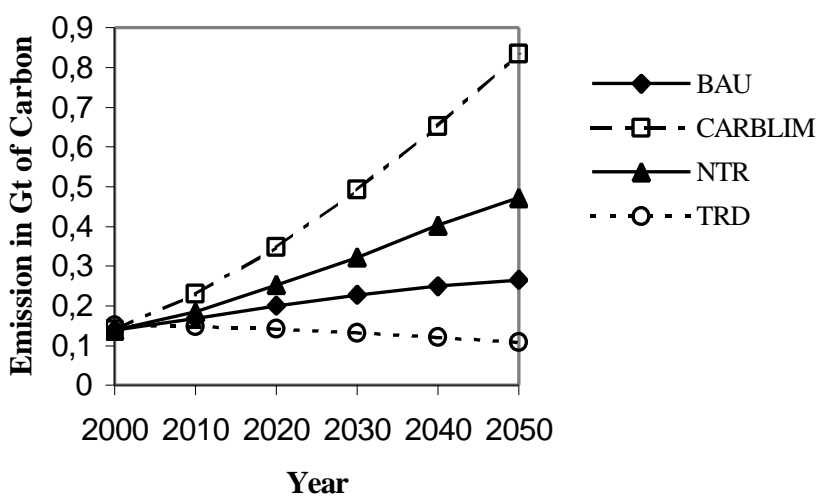

Fig. 2i : Emissions in Country PAS

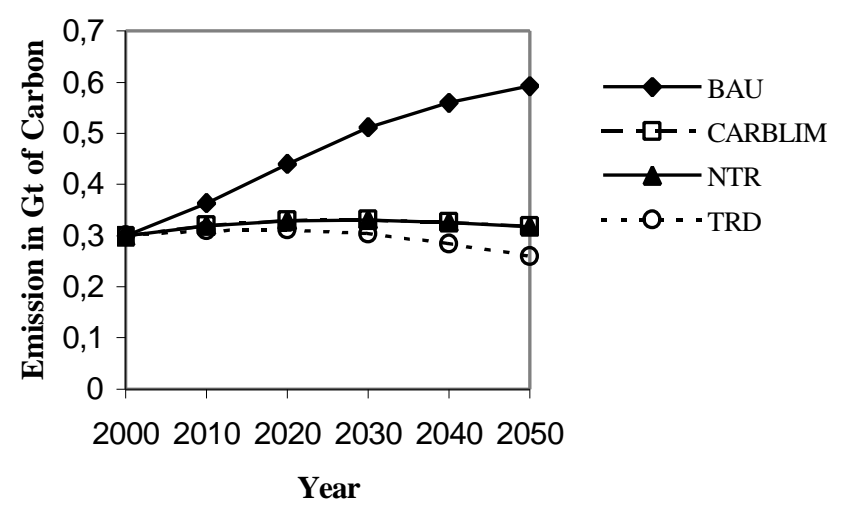

Fig. 2f : Emissions in Country MEA

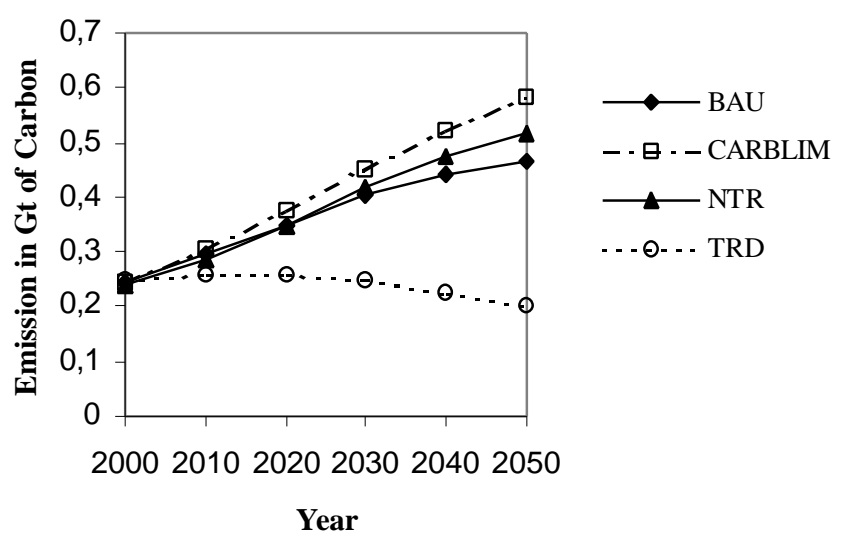

Fig. 2h : Emissions in Country CHN

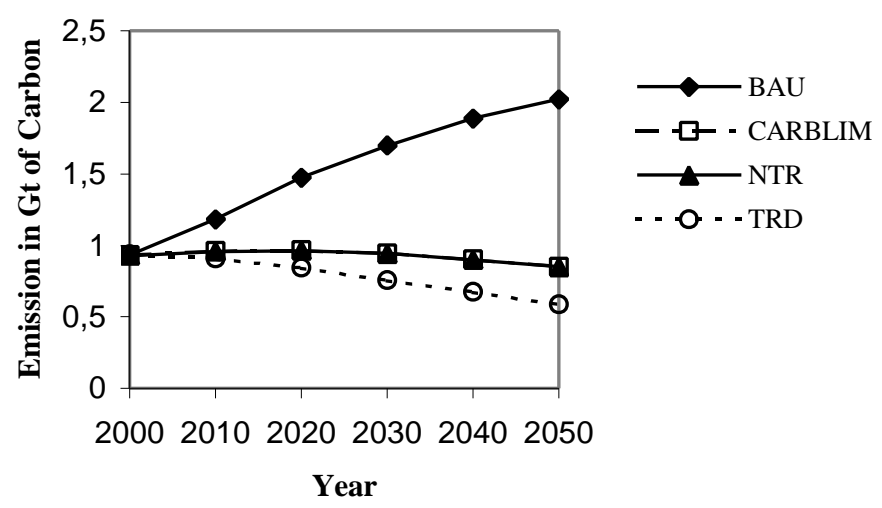

Fig. $2 \mathrm{j}$ : Emissions in Country IDI

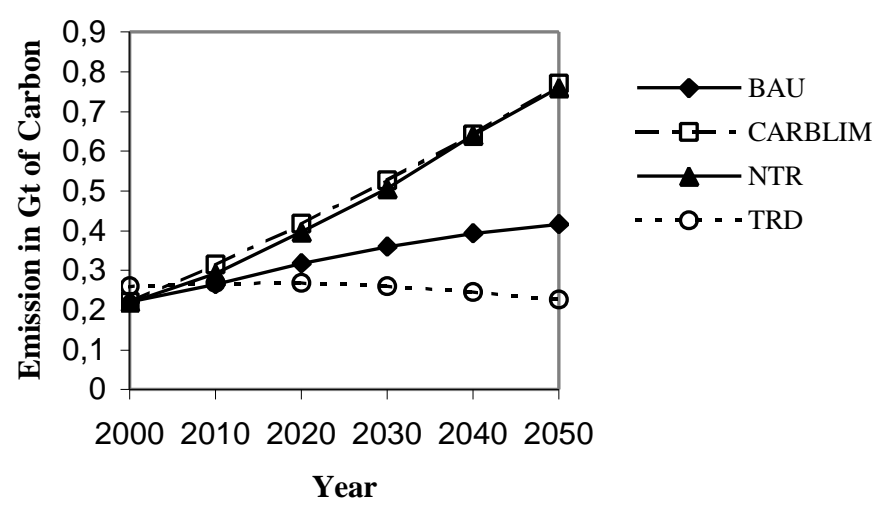


Figures 3 and 4 show the carbon tax trajectories for the NTR case. In addition we have plotted the price trajectory of tradable permits (WORLD) as a reference line to explain the pattern of permit trade emerging from the countries' before trade situation.

There are no carbon taxes under NTR for regions IDI, AFR and MEA. This is simply because $\mathrm{C} \& \mathrm{C}$ does not bind economic growth in these regions. In all other countries $\mathrm{C} \& \mathrm{C}$ constrains economic development more and more over time inducing a continuous increase in marginal abatement costs. In other words, as cheap mitigation options are exhausted over time it gets more and more costly at the margin to substitute away from carbon.

OECD regions (NAM, WEU, PAO) and REC face the highest effective abatement requirements under the $\mathrm{C} \& \mathrm{C}$ proposal and therefore need very high carbon taxes to restrict drastically their carbon use in the long run. On the other hand there are regions LAM, CHN and PAS for which $\mathrm{C} \& \mathrm{C}$ imposes less stringent abatement requirements which translates into relatively lower carbon tax rates.

Comparing regional tax rates in the NTR case, which range from 0 to more than 1500 \$US, there is considerable potential for carbon trading, i.e. global equalization of marginal abatement costs. Countries whose marginal abatement costs under NTR are below the global carbon tax (TRD) will sell permits and abate more emissions. In turn, countries whose marginal abatement costs are above the global tax rate will buy permits and abate less emissions.

Figures 2, 3 and 4 indicate that NAM, WEU, PAO and REC7 buy permit rights whereas IDI8, AFR, MEA, CHN, LAM and PAS sell emission rights.

Emissions trading implies that the group of permit buyers reduce their emissions between 2000 and 2050 by only $70 \%$ of what they would have to in the NTR case. CHN, LMA and PAS abate about 1.3 times as much as they would under NTR. IDI, AFR and MEA do not undertake any abatement in the NTR case; under the TRD regime they do abate roughly 30 percent of their aggregate $B A U$ emissions between 2000 and 2050.

\footnotetext{
${ }^{7}$ In the first decade there is some limited scope in REC for selling emission rights due to low growth projections. After 2010 actual growth projections for this region imply a net buyer position.

${ }^{8}$ In an intertemporal perspective IDI is an important seller of emission rights. Note however that IDI buys carbon rights under $T R D$ at the very beginning of $C \& C$. The increase in lifetime income due to carbon trade is used in part for an increase in consumption during the intitial period. The induced increase in production requires additional purchases of carbon rights - otherwise domestic production would be constrainted by the small initial emission budget of C\&C.
} 
Figure 3: Carbon taxes under NTR below global TRD permit price (WORLD)

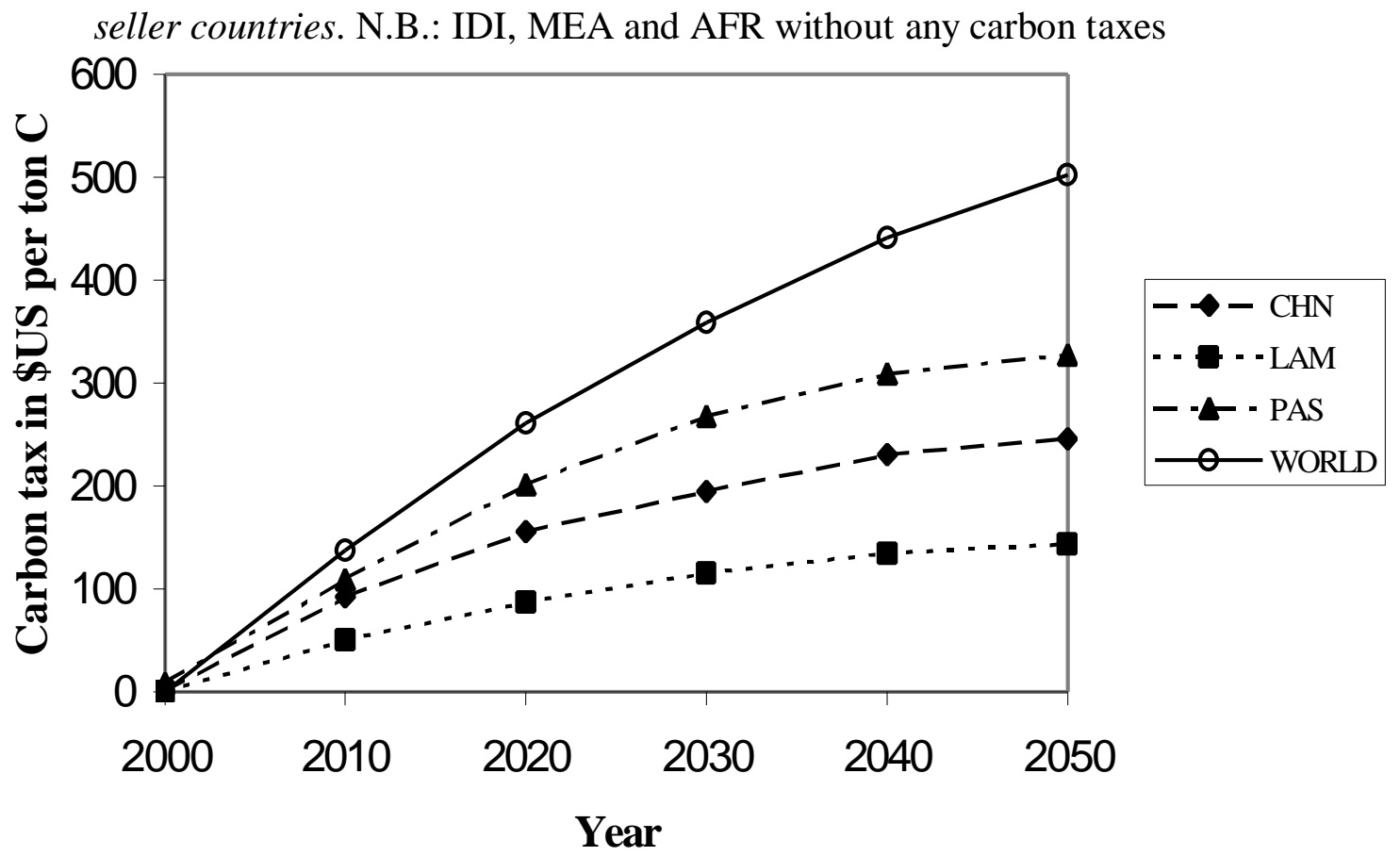

Figure 4: Carbon taxes under NTR above global TRD permit price (WORLD) buyer countries

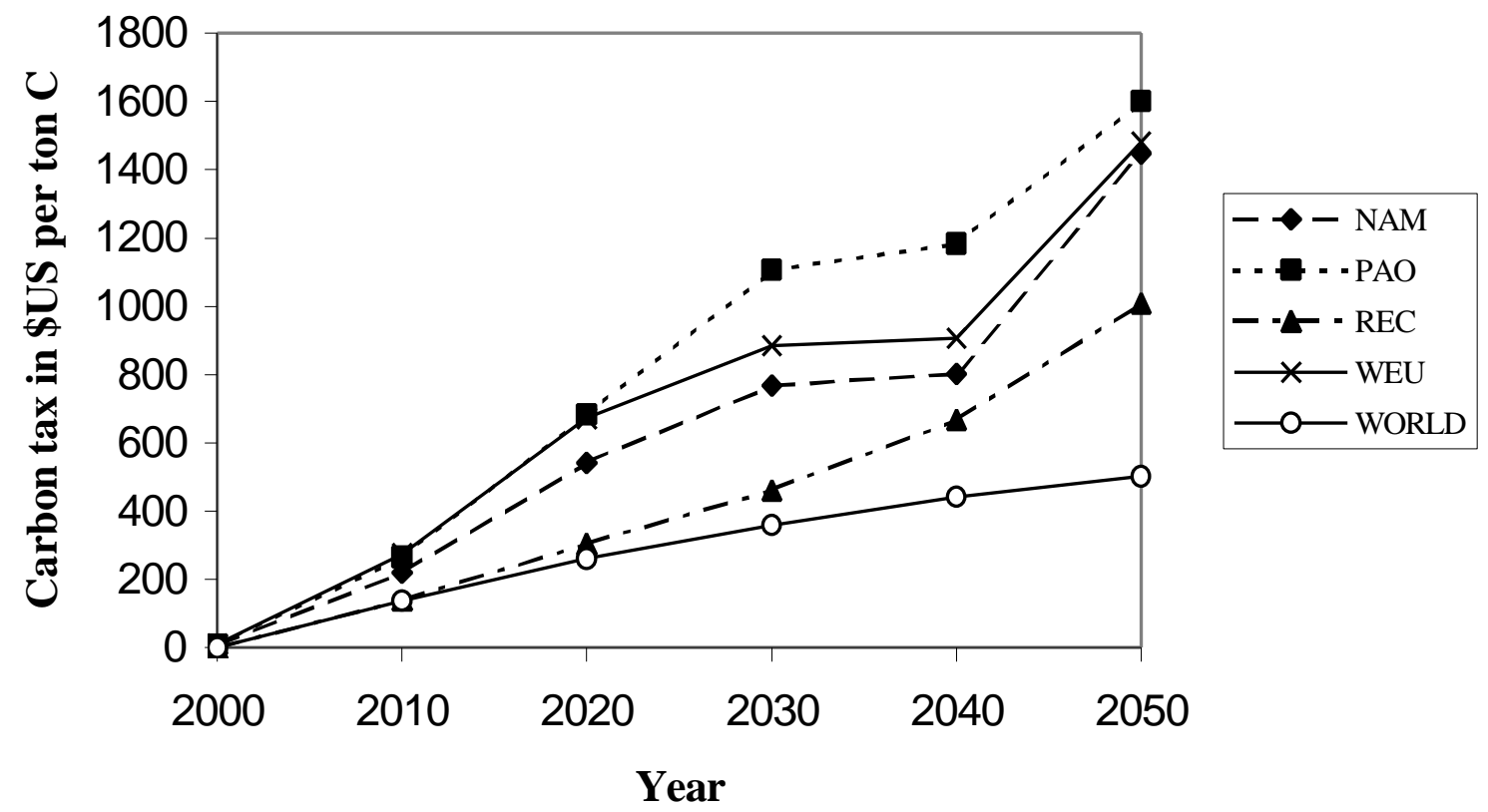




\section{B. Welfare Effects}

The effect of $\mathrm{C} \& \mathrm{C}$ on gross economic welfare ${ }^{9}$ could be measured as the change in real consumption. On a worldwide scale we find that the limitation of carbon emissions over time leads to a decrease in real consumption relative to BAU. This reflects the fact that the restriction of the global carbon emission resource induces significant costs of adjustment towards less carbon-intensive production and consumption. The decrease in consumption is substantially less pronounced in the TRD case than in the NTR case. To illustrate this in quantitative terms: By 2050, the loss amounts to 2.3 percent under TRD and to 5.1 percent under NTR.

Figure 5: World Consumption trajectory - TRD versus NTR (percentage change from $B A U$ )

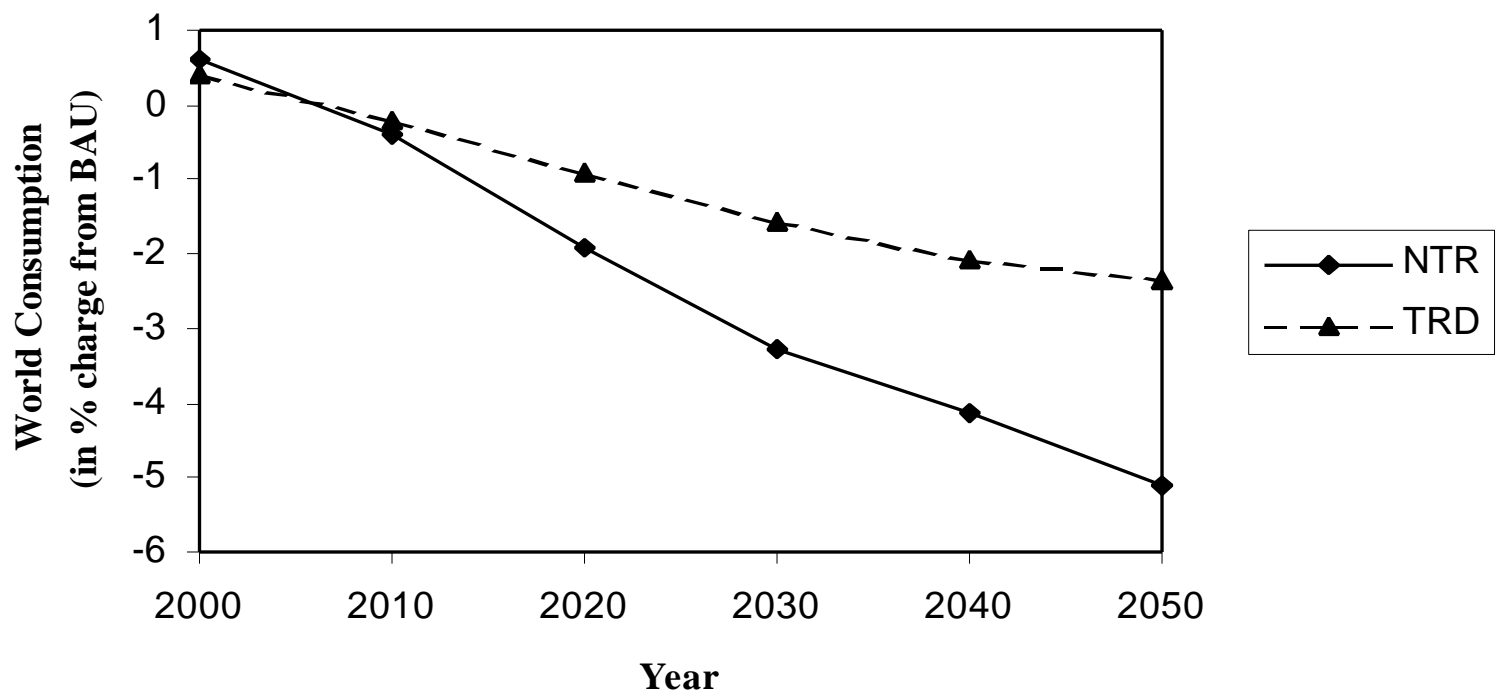

In general, comparison of the trajectories of real consumption does not provide a straightforward welfare measure. When trajectories cross - which in our simulations is the case for all buyers of carbon emission rights (as well as the world in total) - the visual comparison does even not allow for an ordinal ranking of alternative policies but needs to be supplemented by discounting consumption to a given reference point in time. We therefore use an aggregate intertemporal welfare measure which is the Hicksian equivalent variation with respect to lifetime income.

\footnotetext{
${ }^{9}$ Our welfare evaluation is restricted to a cost-efficiency analysis, i.e. we neglect the benefits from an increase in environmental quality (abatement of global warming).
} 
Considering the percentage Hicksian equivalent variation (HEV) in lifetime income as depicted in Table 4, we find that - for our C\&C abatement scenario and model parameterization - carbon trading is universally beneficial.

Table 4: HEV in lifetime income (\% change from $B A U)-N T R$ versus TRD

\begin{tabular}{l|rr} 
& NTR & TRD \\
\hline CHN & -3.02 & -1.08 \\
REC & -9.76 & -8.82 \\
IDI & 0.25 & 17.28 \\
MEA & -3.07 & 2.56 \\
NAM & -3.20 & -2.68 \\
WEU & -1.72 & -1.40 \\
PAO & -1.46 & -1.21 \\
LAM & -1.13 & 0.38 \\
AFR & -2.07 & 17.04 \\
PAS & -0.15 & 0.16 \\
WORLD & -2.26 & -0.99 \\
\hline
\end{tabular}

Most outstanding are the substantial gains from trade in carbon rights for regions IDI and AFR. In fact, these regions do not only benefit dramatically from trade as compared to the NTR case but improve their economic welfare much beyond $B A U$ levels. The same applies though to a much smaller extent - to regions MEA, LAM and PAS. Regions which are still quite adversely affected by $\mathrm{C} \& \mathrm{C}$ under $T R D$ include the OECD regions (NAM, WEU and PAO) and the reforming economy countries (REC) as well as China (CHN). All regions with exception of IDI experience a net welfare loss from $C \& C$ in the no trade case. The welfare implications for IDI, MEA and AFR under NTR emphasize the importance of international spill-overs. In other words: Though these regions do not have to undertake domestic abatement they nevertheless are affected by abatement action in other countries through international markets, i. e. changes in international prices (the terms of trade). ${ }^{10}$ Before we explain the economic implications at the regional level let us briefly summarize the key factors that will determine the welfare impacts of C\&C:

\footnotetext{
${ }^{10}$ Terms of trade can be used to determine whether a country will benefit or lose from the change in international prices. Terms of trade are measured as the ratio in value terms of a country's imports to its exports. A positive change in the terms of trade then means that the country has to export less for a given amount of imports, i.e. the country experiences a welfare gain from the change in international prices.
} 
- A country's cost to abate carbon emissions depend critically on its baseline economic development. The latter determines baseline emission growth which in turn implies the effective cut-back requirement with respect to an exogenous emission target profile (in our case: $C A R B L I M)$. Greater required reduction in carbon emissions as a percentage of baseline emissions leads to larger abatement costs.

- As to spill-over effects from international markets the trade patterns of a region significantly determines the extent to which this region will gain or lose from changes in international prices. With respect to carbon abatement and our sectoral disaggregation it is useful to distinguish spill-overs from two major international markets:

- fossil fuel markets: A larger cutback in global fossil fuel consumption depresses the international prices of fossil fuel (the magnitude of depression depends to a large extent on the underlying supply elasticities). In this respect a region which imports fossil fuels will benefit from the contraction of world fuel consumption whereas a country which exports fossil fuels will suffer. ${ }^{11}$

- non-energy markets: Due to product heterogeneity associated with the Armington assumption for non-energy macro good trade, countries are able to pass on an increase in production prices to other countries. Whether a country will experience a terms of trade loss or gain on the macro good markets depends on its initial trade shares and elasticities (of export supply and import demand) as well as differences in the costs of producing the macro good induced by $\mathrm{C} \& \mathrm{C}$. The price differentials for Armington goods of the same variety across regions determine the substitution effects in international trade, that is whether a country will rather lose or win export markets.

While at the global level terms of trade effects should net out to zero it is clear that at the single country/region level the welfare implications will have opposite directions. ${ }^{12}$ Terms of trade effects are the reason why - in a general equilibrium framework - trade in permits need not necessarily be beneficial for all countries. ${ }^{13}$

\footnotetext{
${ }^{11}$ If a region at the same time is a net exporter of some fuel and a net importer of some other fuel the aggregate fossil fuel market effect is ambiguous.

${ }^{12}$ The gains for one country translate into symmetric losses for other countries.

${ }^{13}$ Though a specific country in the first place will benefit from carbon trade there are secondary terms of trade effects which could offset (or enhance) the primary benefits.
} 
To explain the gross welfare implications associated with carbon emission constraints in open economies we employ the decomposition method as described in Böhringer and Rutherford (1999b). This decomposition allows for a break down of the aggregate economic effect into a domestic policy effect (i. e., domestic adjustment abstracting from changes in international prices) and international spill-overs (i. e., changes in the terms of trade). Table 5 summarizes the outcome of the decomposition for the NTR case.

Table 5: Decomposition of HEV in lifetime income under NTR (in \% from $B A U$ )

\begin{tabular}{l|rrrr} 
& $\mathrm{A}$ & $\mathrm{B}$ & $\mathrm{C}$ & $\mathrm{D}$ \\
\hline IDI & 0.00 & 1.70 & 0.25 & 0.25 \\
CHN & -2.07 & -1.38 & -0.95 & -3.02 \\
MEA & 0.00 & -3.19 & -3.07 & -3.07 \\
NAM & -3.10 & -0.11 & -0.11 & -3.20 \\
WEU & -1.80 & 0.11 & 0.08 & -1.72 \\
PAO & -1.49 & 0.02 & 0.03 & -1.46 \\
REC & -9.30 & -0.73 & -0.46 & -9.76 \\
LAM & -0.06 & -0.57 & -1.06 & -1.13 \\
AFR & 0.00 & -1.41 & -2.07 & -2.07 \\
PAS & -0.36 & 0.33 & 0.22 & -0.15 \\
\hline
\end{tabular}

A: Domestic policy effect of abatement keeping international prices at the $B A U$ level

B: Fossil Fuel Price Effect: Welfare effect when we account for changes in international fuel prices but keep the price of the macro good at the $B A U$ level

C: Isolated terms of trade effect (D - C)

D: Full carbon abatement effect $(\mathrm{A}+\mathrm{C})-$ see column NTR of Table 4

The domestic policy effect (column A of Table 5) reports the welfare impacts of carbon constraints assuming that international prices are unaffected from the domestic (tax) abatement policy. As expected for an initial situation without distorting taxes, the welfare impact of domestic emission abatement is negative. Emission limits require a reduction in fossil fuel consumption which causes domestic industries to substitute towards less emission-intensive, more costly manufacturing and production techniques. In addition, fuel for final consumption becomes more expensive. The rise in the real consumption price index implies a loss in real income (welfare) for households. The magnitude of the inframarginal welfare loss associated with the domestic abatement policy depends on a number of factors such as the effective reduction requirement with respect to the baseline, the initial energy (emission) intensity, substitution elasticities, etc. By definition, the domestic policy effect is zero for regions IDI, AFR and MEA which do not have to undertake any carbon abatement. 
As outlined above an important determinant for the sign and magnitude of the aggregate terms-of-trade effects are changes in international fossil fuel prices togehter with the region's initial fossil fuel trade position. The welfare implications of spill-overs from international fossil fuel markets at the single region level are reported in column B of Table 5. We see that IDI, WEU, PAO and PAS experience welfare gains from changes in international fuel prices whereas CHN, MEA, NAM, REC, LAM and AFR face welfare losses. Not surprisingly MEA as a major exporter of oil suffers most from the fall in fossil fuel prices. ${ }^{14}$ $\mathrm{CHN}$ - an important future coal exporter - and REC which - supplies large quantities of gas to world markets - are also affected negatively from the price decrease on international fossil fuel markets.

Column $\mathrm{C}$ of Table 5 reports the welfare implications of total terms of trade changes across regions. Jointly with column B we see that price changes on the international markets for the non-energy macro good impose major welfare losses for regions IDI, AFR and LAM whereas CHN, MEA and REC can partially offset the negative welfare impacts due to the fall in fuel prices. As a consequence of their macro good trade relations with high carbon tax countries (NAM, PAO or WEU) IDI, AFR and LAM turn to net tax burden importers rather than net tax burden exporters. The opposite applies for regions CHN, MEA and REC.

The transition from the NTR regime to the TRD regime significantly changes the magnitude and distribution of costs associated with C\&C. First of all, trade of permits - in our scenario - constitutes a win-win strategy such that prospects for multilateral cooperation are enhanced. Permit trade turns out to be most beneficial for those regions which do not exploit their carbon budget to the full extent under NTR. For these regions the price of emission rights increases dramatically from zero to the world market permit price under TRD. Their abundant costless emission rights under NTR become a valuable international resource which provides them with substantial addition net income.

As to the sign of welfare changes it is remarkable that trade in permits provides sufficient efficiency gains for MEA, AFR, PAS and LAM to turn from a net loser position into a net winner situation as compared to their baseline economic development. The OECD club and $\mathrm{CHN}$ will still face economic losses from $\mathrm{C} \& \mathrm{C}$ but for $\mathrm{CHN}$ this loss drops dramatically. By far worst affected from C\&C under both $N T R$ and $T R D$ are the reforming economic countries (REC). We can see from column A of Table 5 that the main reason for the welfare

\footnotetext{
${ }^{14}$ Likewise oil exporting AFR and LAM face a substantial decline in export revenues from oil sales.
} 
losses is the costly adjustment of highly energy-intensive production and consumption towards a significantly less emission-intensive economic structure.

\section{Summary and Policy Implications}

In this paper we have used a dynamic multi-region general equilibrium model of the world economy to assess the economics of a scenario which entails contraction of carbon emissions joint with convergence towards equal per capita emission rights over the time horizon 2000 through 2050. Our C\&C scenario implies that global emissions have to drop from more than $11 \mathrm{Gt}$ of carbon in 2050 in the baseline to just $4.4 \mathrm{Gt}$ under C\&C.

At the global level the associated economic costs in terms of Hicksian equivalent variation in lifetime income range from -0.99 percent under tradable permits to -2.26 percent under non-tradable emission right. The magnitude of efficiency gains from trade reflects the tremendous range in marginal abatement costs across the different regions [between zero and 1500 \$US (in 2050)].

At the regional level the abatement requirements associated with $\mathrm{C} \& \mathrm{C}$ differ quite a lot. The OECD countries, CHN and REC will have to reduce their emissions substantially and will incur significant economic losses. By contrast, there will be no abatement requirements for IDI, AFR and MEA under NTR. Nevertheless, they will be adversely affected by C\&C in the NTR case. This makes quite transparent how important spill-over effects from international markets (i.e. terms of trade effects) are for the aggregate welfare implications of C\&C. IDI is the only region which can improve economic welfare under $N T R$ as compared to $B A U$ because the depreciation of international fuel prices in conjunction with their large endowment in carbon rights provides them with a substantial competitive edge in producing more energy-intensive goods. Disregarding the latter case, we conclude that it will be difficult to implement C\&C under the $N T R$ regime as it can not be expected that major developing regions are willing to bear a larger share of the abatement costs.

Trade in permits improves the economic well-being of all regions as compared to a NTR regime. Thus, politically, it will be much easier to achieve an agreement to $\mathrm{C} \& \mathrm{C}$ when the carbon permit regime allows for "where"-flexibility in abatement (trade). Major opponents to carbon restrictions from the developing world such as AFR, LAM, MEA or IDI could be able to improve their economic welfare even over $B A U$ levels. To put it differently, $C \& C$ under $T R D$ works as an implicit transfer of economic resources from the developed world to the developing world while assuring that also the developed world benefits from carbon trade as 
compared to the NTR scenario. CHN still suffers a welfare loss under TRD but this loss is dramatically lower than under NTR such that political resistance towards $\mathrm{C} \& \mathrm{C}$ might be expected to be also substantially lower. REC is the principal loser of C\&C both under TRD and $N T R$ which results from their initially high emission-intensive production and consumption structure. Our results indicate a need to think about a compensation mechanism for the reforming economy countries (REC) in order to reduce their adjustment costs. Again, the prospects to reach agreement on compensation for REC under C\&C will be much higher if financial transfers can be paid by the potential efficiency gains arising from a global tradable permit system.

\section{References}

Armington, P.S. (1969), A Theory of Demand for Products Distinguished by Place of Production, IMF Staff Papers 16, 159-178.

Bernstein, P.M., Montgomery, W.D. and T.F. Rutherford (1997), World Economic Impacts of US Commitments to Medium Term Carbon Emissions Limits, Final Report to the American Petroleum Institute: Charles River Associates, Report No. 837-06.

Böhringer, C. and T.F.Rutherford (1999a), World Economic Impacts of the Kyoto Protocol, in Welfens, P.J.J, Hillebrand, R. and A. Ulph (Eds.): Internalization of the Economy, Environmental Problems and New Policy Options, Springer, Heidelberg/New York, forthcoming: 1999.

Böhringer, C. and T.F. Rutherford (1999b), Decomposing General Equilibrium Effects of Policy Intervention into Open Economies, ZEW working paper, Mannheim.

Böhringer, C., Jensen, J. and T. F. Rutherford (1999), Energy Market Projections and Differentiated Carbon Abatement in the European Union, ZEW discussion paper No. 99-11, Mannheim.

Bohm, P. and B. Larsen (1994), Fairness in a Tradable Permit Treaty for Carbon Emissions Reductions in Europe and the former Soviet Union, Environmental and Resource Economics 4, 219-239.

Bos, E. et al. (1992): World Population Projections 1992-1993 Edition, Washington: Bank for International Reconstruction and Development 1992.

Global Commons Institute (1997), Contraction and Convergence: A Global Solution to a Global Problem, http://www.gn.apc.org/gci/contconv/cc.html, updated 18/07/97.

Greenpeace (1998), UN Framework Convention on Climate Change, meeting of subsidiary bodies, position paper, 2-12 June, Bonn.

Grubb, M. (1989), The Greenhouse Effect: Negotiating Targets, Royal Institute of International Affairs, London.

Herold, A. (1998), Hot Air and the Kyoto Protocol. In: WWF/ Forum on Environment\&Development (Eds.).: Emissions Trading in International Climate Protection, proceedings, Bonn, 50-53. 
Houghton, J.J. et al. (eds.) (1996), Climate Change 1995 - The Science of Climate Change, Cambridge University Press.

IEA (1994), International Energy Agency, Energy Prices and Taxes / Energy Balances of OECD and NonOECD Countries, Paris: IEA publications.

IIASA (1998), IIASA/WEC Global Energy Perspectives, http://www.iiasa.ac.at

Lindbeck, A. (1983), The Recent Slowdown of Productivity Growth, Economic Journal, 1983.

McDougall, R.A. (1995), The GTAP 3 Data Base, Center for Global Trade Analysis, Purdue University.

Morrisette, P. and A. Plantinga (1991), The Global Warming Issue: Viewpoints of Different Countries, Resources 103, 2-6.

Rose, A. and B. Stevens (1996), Equity Aspects of the Marektable Permits Approach to Global Warming Policy, Paper presented at the Seventh Annual Conference of the European Association of Environmental and Resource Economics, June 1996, Lisbon, Portugal.

Welsch, H. (1993), A CO 2 Agreement Proposal with Flexible Quotas, Energy Policy 21, 748-756. 